\title{
Learning to Embody a Social Justice Perspective in Couple and Family Therapy: A Grounded Theory Analysis of MFTs in Training
}

\author{
Tori Morrison $^{1}\left[\right.$ D $\cdot$ Midori Ferris Wayne ${ }^{1} \cdot$ Tahlia Harrison $^{2} \cdot$ Emily Palmgren $^{1} \cdot$ Carmen Knudson-Martin $^{1}$
}

Accepted: 24 January 2022 / Published online: 10 February 2022

(c) The Author(s), under exclusive licence to Springer Science+Business Media, LLC, part of Springer Nature 2022

\begin{abstract}
This action research study explores how four MFT students shifted from a cognitive understanding of equity and power to an intrinsic and automatic internalized process as we participated in research in which we observed, coded, and engaged in structured reflexive conversations about relational power using a data bank of Socio Emotional Relationship Therapy sessions. We reviewed and analyzed ten of our recorded two-hour reflexive conversations to develop grounded theory that explains our experience of learning to embody a relational power lens, which consists of five interconnected phases: (a) developing a theoretical understanding of relational power, (b) critically observing live therapy, (c) noticing and attending to the felt sense of witnessing power, (d) engaging in transformative conversation, and (e) applying to personal practice. Our findings provide guidance for clinical training programs who wish to facilitate the experience for clinicians-in-training to understand and address societal power processes in clinical practice.
\end{abstract}

Keywords Clinical training $\cdot$ Supervision $\cdot$ Social justice $\cdot$ Couple therapy $\cdot$ Socio-emotional $\cdot$ Relationship therapy $\cdot$ Power and equity $\cdot$ Relationships

Couple and family therapy training programs are called upon to facilitate "development of competencies in understanding and applying knowledge of diversity, power, privilege, and oppression" (COAMFTE Foundational Curriculum Area 3, version 12.5). Considerable literature addresses why this attention to social justice is important (e.g., Rambo, 2018; Watson et al., 2020), and an emerging body of work is beginning to detail what equitable, socially responsible practice looks like (Almeida, 2018; Baima \& Sude, 2020;

Tori Morrison

tori@narrativerootstherapy.com

Midori Ferris Wayne

mferriswayne@lclark.edu

Tahlia Harrison

tahlia.harrison@duke.edu

Emily Palmgren

emily@ realgoodtherapypdx.com

Carmen Knudson-Martin

carmen@1clark.edu

1 Lewis \& Clark College, (Marriage, Couple, and Family Therapy), Portland, OR, USA

2 Duke University, (Bioethics, Tech Ethics \& Policy), Durham, NC, USA
D’Arrigo-Patrick et al., 2017; Holyoak et al., 2020; McDowell et al., 2019; Pandit et al., 2014). However, there is limited guidance regarding how one learns to apply these social justice-related principles into clinical practice (Baima \& Sude, 2020). Learning to recognize societal-based power inequities and be accountable regarding them is particularly challenging (ChenFeng, et al., 2017; Knudson-Martin, 2013; Mock, 2019; Zetzer, 2016).

We are a group of family therapy students and a clinical supervisor/educator who were involved in participatory action research (Coghlan \& Brannick, 2005) studying how power and privilege processes are present and addressed in video-recorded therapy sessions in our training clinic. One of the goals of this project was to identify the learning processes involved: how we acquired an understanding of what it meant to work with societal power processes as we coded and discussed these videos and absorbed this new awareness into our practice. Though this research grows out of our own experience and contexts as learners, the grounded theory model of our learning process identified in this study may be useful to family therapy educators, supervisors, and students in considering how to promote the development of clinical competencies relating to power, privilege, and oppression in their settings. 


\section{Literature Review: Learning to Address Societal Power Contexts}

Like Hardy (2017), we began with the assumption that "therapists, supervisors, and educators have a role in promoting social justice, equity, and fairness [in relationships] and in the wider community... that the skills we endeavor to teach and wisdom we hopefully impart is never divorced from the larger sociocultural context" (p. 25). However, social responsibility tends to remain a special issue that is not centered in family therapy training (Hardy \& McGoldrick, 2019) or is treated as advocacy work separate from clinical practice (Holyoak et al., 2020). In an effort to bring social justice-focused training to the forefront, this study drew on literature regarding the foundations of social justice-informed MFT training and related research on therapist development.

\section{Social Justice Foundations}

Bell (2007) defined the goal of social justice education as "providing a framework for questioning and understanding our practices... and to develop a sense of agency and the capacity to interrupt and change oppressive patterns and behaviors in themselves and in the institutions and communities of which [we] are a part" (p. 2). In family therapy, learning to recognize power processes and sensitivity to sociocultural contexts are key (Almeida \& Tubbs, 2020; Castronova et al., 2020; Falicov, 2014; McDowell et al., 2019; Stone \& ChenFeng, 2020).

We follow McDowell's (2015) definition of power as "the ability to prevail over another and impose one's will" (p. 6). From a relational perspective, power is not a personal property, but may be viewed as the relative influence of one person or group on another and the interpersonal patterns that arise from inequitable social and cultural contexts in which some interests and sources of knowledge are deemed more credible and important than others, and individuals internalize these contextual messages about themselves (Knudson-Martin et al., 2021; Stone \& ChenFeng, 2020). From this lens, power positions can be identified by noticing whose needs and interests are supported by relational dynamics even when they go unstated. These power dynamics are not a static relationship of unidirectional control; opportunities for influence within relationships are constrained by intersectional societal frameworks such as those around gender, sexuality, race, and economics, yet also remain fluid from moment-to-moment (McDowell, 2015). Attunement to sociocultural context comprises attention to broad structural issues but also to unique and personal lived contexts, and "refers not only to awareness of social systems, culture, and power, but to the willingness to pay close attention and be responsive to the experience of others" (McDowell et al., 2019, p. 1).

Learning to work with concepts of power and sociocultural context impacts the role of the therapist. Despite good intentions, so-called "neutral" approaches inadvertently reinforce inequitable power processes and impede therapeutic progress (Dolan-Del Vecchio, 2019; Hardy \& McGoldrick, 2019; Murphy \& Hecker, 2020). In contrast, placing equity at the center of therapy requires therapists to be aware of their positionality and interact flexibly and responsively with each person to actively interrupt and transform relational power imbalances (Knudson-Martin \& Huenergardt, 2010; Knudson-Martin et al., 2015).

\section{Therapist Development}

C/MFT education programs typically begin by guiding students in the cognitive development of theoretical approaches which may include critical, postmodern, and modernist perspectives that do not readily integrate and initially can be experienced as disruptive or unsettling (Hoff \& Distelberg, 2017; Hoff et al., 2018). Even when classroom focus includes a social justice orientation, this emphasis is not often reflected in later practice (Almeida et al., 2008). Practices identified to enhance learning about diverse perspectives, such as critical self-reflection assignments and experiential opportunities for cultural immersion (Laszloffy \& Habekost, 2010), do not always translate to meaningful or holistic clinical integration, particularly when programs lack theory-into-practice components (Piercy et al., 2016). Fulfilling social justice oriented training experiences which increase "the likelihood that therapists will bring their whole selves into their work" (Stone \& ChenFeng, 2020, p. 74) have not often received research attention.

Development of therapists accountable to social justice involves restructuring the curriculum so that the sociocultural context of therapy is present throughout training (Hardy \& McGoldrick, 2019; McDowell \& Shelton, 2002; McGeorge et al., 2006). MFT educators and supervisors are advised to initiate conversations about power and privilege and sociocultural context and promote critical self-reflection and awareness (ChenFeng et al., 2017; Hardy \& Bobes, 2017). They are also encouraged to support therapist development by helping supervisees focus on contextual issues in case conceptualization, attune to the social context of emotion, and manage power processes (Kim et al., 2017). According to Falicov (2014), "If supervisees gain a better understanding of how injustice has affected clients' lives and help them become better prepared to deal with present and future injustices, the treatment has been at least partially an act of social justice" (p. 46). 
Training in how to address sociocultural issues tends to be cognitively oriented (Petty-John et al., 2020). Little emphasis is placed on the process of experiencing a therapeutic approach, what Rober (2020) identified as skilled intuition that develops out of reflecting on moment by moment practice and one's responses to it. Intentional awareness is especially important since many clients and therapists are unaware of how inherent sociocultural patterns create invisible dynamics that maintain unequal power and hamper intimacy (Knudson-Martin \& Mahoney, 2009).

Although Nixon et al. (2010) have observed that research into how students learn to address contextual issues is limited, one study in particular explored these issues from a participatory action research approach that we found especially insightful. Esmiol and colleagues (2012) explored how therapists-in-training develop a contextual consciousness to address social justice and issues of power through clinical practice. They identified three processes that impacted their development. The first was heightened awareness of broader sociocultural contexts in clinical settings, which they developed through study of theoretical frameworks as well as through clinical experimentation to integrate this learning. The second was reflective questioning to challenge their previous assumptions and methods, and the third involved intentional commitment to a new, more personally meaningful contextual lens.

\section{Purpose of the Study}

Because there is ample literature supporting the importance of developing self-awareness through engagement in critical conversation, but little about moving from social justice theories to practice (Nixon et al., 2010), we were drawn to participate in a research group that focused on how therapists address sociocultural and power processes. The study used Socio-Emotional Relationship Therapy (SERT), an approach that places attention to power and sociocultural attunement at the center of practice, as an orienting framework (Knudson-Martin \& Huenergardt, 2010; Knudson-Martin et al., 2015, 2021). To help advance knowledge regarding how therapists learn to translate these social justice theories into practice, we focused on our own learning experiences as we moved from a cognitive understanding of social justice concepts to a felt and experiential understanding of relational power in the practice of couple therapy. The purpose of the analysis presented here was to develop grounded theory that identified how such learning occurred for us. We sought to understand these issues more fully ourselves, while also providing some clarity for other training programs, supervisors, and therapist trainees pursuing similar goals.

\section{Method}

To reach a better understanding of our own learning process, we utilized a participatory action approach (Coghlan \& Brannick, 2005) implemented with Charmaz's grounded theory methodology (2014). Grounded theory methods are systematic, yet offer flexible guidelines for the collection and analysis of qualitative data, allowing the theories to be constructed or "grounded" in the data itself (Charmaz, 2014). Grounded theory is especially useful in identifying and studying how processes relate to one another. According to Charmaz, analyses are not separate from the researchers. Our analysis was an interpretive process as we moved from initial coding to separate, sort, and synthesize the data we were creating to developing theory to explain our observations about our learning process.

We also drew on Mertens's (2007) transformative paradigm, which recognizes attention to inequality, injustice, and a shared sense of responsibility as essential to the role of the researcher. The participant-up approach of grounded theory methods is compatible with this orientation to research. The transformative paradigm centers the importance of researchers actively engaging in work that counters their own biases and assumptions through engaging in critical self-reflection (Mertens, 2009).

The Participatory Action Research (PAR) stance afforded adaptability amenable to examining our selfexperience (Coghlan \& Brannick, 2005). PAR allows for ongoing change and evaluation of processes, with the goal of improving practice/training overall (Esmiol et al., 2012). We applied the transformative paradigm framework to address issues of social justice in methodological decisions and Charmaz's (2014) grounded theory guidelines to systematically organize our analysis. What emerged was the development of a grounded theory model that explained our experience of "embodying" a relational power lens.

\section{Participant Researchers}

Our analysis team became the study sample. We were at varying developmental stages of our MFT program; three of us were third-year students and one was second-year. A developer of the SERT approach was our MFT faculty researcher and had supervised the cases we studied. Common to all of our experience was moving through coursework in our MFT program that centered attention to social justice. We had studied how societal discourses, power processes, and the biological, psychological, and social systems impact individual and relational development and thus the process of case conceptualization and treatment 
planning. Application of critical, social constructionist, and systems theories was woven throughout coursework and core to the expected clinical competencies.

As part of a program committed to the development of culturally responsive family therapists, we had been engaged in continual, active dialogue to create awareness of how social structures promote equality or oppression (McDowell \& Shelton, 2002) and of our social locations within dominant power structures (Hardy \& McGoldrick, 2019; McDowell et al., 2003; McGeorge et al., 2006). By engaging with SERT in our coursework and experiential learning, we had been afforded a framework for observing and addressing power processes that served as a sensitizing lens for the clinical aspect of this study (Charmaz, 2014). This included recognition of three phases of SERT clinical competencies: positioning, interrupting, and practicing. The SERT process begins by socioculturally attuning to relational power inequities (positioning). Therapist interventions shift in-the-moment power processes (interrupting), and help clients create new ways of relating and practicing shared responsibility (practicing) (Knudson-Martin et al., 2021).

Our research team is all white or white passing, female, and differ in our sexual orientations, relational structures, ages, and economic statuses. In our clinical internships we worked with clients who inhabited varying identities and locations across sexuality, gender, race and socioeconomic status. With our shared training background as culturally responsive family therapists, and the implementation of Merten's transformative paradigm, the interaction of our varying identities and locations were regularly considered and brought forward in the process of each step of our study.

\section{Data Creation}

This analysis was part of a larger study approved by our institution's Internal Review Board (IRB). Our learning occurred as we viewed couple therapy sessions with the goal of identifying the factors involved in determining adherence to the SERT model. A primary principle of this model is that equitable partnerships mutually support the well-being, needs, and interests of each person (KnudsonMartin \& Huenergardt, 2010; Knudson-Martin, et al., 2015). We therefore focused on how therapist interventions may or may not have perpetuated power imbalances between partners, such as who was attuning to whom, who is willing to demonstrate vulnerability, accept influence, or who takes responsibility for the relationship (Knudson-Martin et al., 2015). Observed cases were theoretically selected from a data bank of SERT sessions conducted in our training clinic by prior third-year MFT student therapists supervised by developers of the SERT model or seen by program faculty. Clients provided informed consent to use their video recordings for research. The data bank housed about 130 sessions of varying intersections and identities of therapists and clients. The faculty researcher's familiarity with the cases in the data bank allowed us to select cases to represent a range of clinical processes and ongoing analytic questions as they arose in our study (Charmaz, 2014).

Without having access to client records, all the couples we observed appeared to share cisgender identities and monogamous orientations. Most couples appeared white, heterosexual, and able-bodied; two couples may have been mixed-race, two couples had one partner identifying with a physical disability, and one couple identified as gay. Relational issues were most prominent to their presenting concerns and were often centered around communication, grief and loss, mixed family conflict, co-parenting issues, and financial stress. The observed therapists were primarily white or white passing and represented diversity in gender and sexual identities.

Data for analysis of our learning processes was created in two phases: structured and open coding of video sessions and reflexive conversations.

\section{Phase I: Structured and Open Coding of Video Sessions}

Data creation began by watching and coding therapy sessions with experienced therapists and with therapists in training. We identified when observed therapists demonstrated characteristics and interventions congruent with the SERT model. We also identified power processes and perceived power imbalances, missed opportunities for sociocultural attunement, and the impact of power on the therapeutic process. To guide and organize our thinking, we used a scale from zero to three to record our observations and provide a basis for discussion. This scale included four categories: therapist adherence to SERT, transforming the power imbalance, sociocultural attunement, and client responsiveness. In addition to using the scale, we used open coding to describe specific clinical observations. For example, when a therapist focused on female responsibility for the relationship, but accepted her male partner's denial of responsibility without further exploration (e.g., Smoliak et al., 2021), we coded this as zero adherence to SERT and labeled it as perpetuating a power imbalance.

After initial coding, we wrote notes about each session to describe our individual awareness and perceptions of power processes, social justice, and SERT, which provided topics for the reflexive conversations of the following phase.

\section{Phase II: Reflexive Conversations}

As we coded and discussed the clinical session in phase I above, we noticed shifts within ourselves. To tighten our focus toward our learning process, we re-watched segments of therapy sessions related to our prior codes and engaged in 
reflexive conversations about our observations, more intentionally focusing on our own response to what we observed in our analytic coding process. These reflexive conversations were loosely guided by three questions: a) What power processes did you observe? b) What was your experience witnessing these power processes? c) What might you take away from this observation? Shifting our research meetings to Zoom due to the COVID-19 pandemic made video, audio, and written transcripts available to us from these reflexive conversations.

\section{Analysis: Developing Grounded Theory}

We employed Charmaz's (2014) steps to grounded theory analysis of the transcripts of our reflexive conversations described above. These include open coding, focused coding, and selective coding.

\section{Open Coding}

We began with at least two team members open coding transcripts of each of our ten recorded two-hour reflexive conversations. We read each transcript line by line to identify and name processes that occurred within our reflexive conversations and then compared these codes with our cocoders. For example, when one of us described her internal anxiety to explicitly name power processes in her own practice after witnessing a taped session, we coded this as "hesitancy to address power in personal clinical practice." And when another of us reflected on their recent discomfort in bringing up power processes in their personal practice, we also coded this as "hesitancy to address power in personal clinical practice." However, when one of us described experiencing something similar as the clients in the video in her own personal relationship, we coded that as "therapist reflects on own similar relational experience." By engaging in this constant comparison process we were able to begin exploring the content and meaning in our data through continual review of the variations, similarities, and differences (Charmaz, 2014).

\section{Focused Coding}

We used focused coding to organize our codes into groupings that began to create a clear pathway to explaining our learning process. For example, the previously mentioned code was more formally grouped together with several similar codes and listed under the category "reflection on personal practice." And, all the examples relating to our own practice were categorized as "application to personal practice." The various ways of relating to emotional response of witnessing power were coded "noticing and attending to the felt experience of witnessing power." Throughout this phase of coding and beyond, we maintained analytic memos to further explore our understanding of the coded segments and regularly met with each other to challenge and check ourselves in order to deepen an ethical and honest evaluation of our data. We also recorded these discussions in order to reference them for continued understanding of our evolving process.

\section{Selective Coding}

Once we identified our coding process to be saturatedhaving found no new concepts to code and categorize-we began to theoretically analyze how our categories of codes worked together to develop a descriptive illustration of our learning process. Our feeling of embodiment of a relational power lens into both our beings and our practice-a felt-sense augmented through the process of observing and coding through this lens-became the core experience around which we organized the other focused codes into clear and distinct aspects, which evolved into a five-dimension grounded theory to explain our process of learning to embody this lens. The grounded theory we developed is not separate from our intersectional identities as researchers and was inherently informed by our social positioning (Charmaz, 2014).

\section{Findings: Developing an Embodied Relational Power Lens}

By observing and critically analyzing couple therapy sessions, engaging in reflexive discussion of those observations, and reflecting on the impact of these experiences, we identified a process of embodying a relational power lens within ourselves. We developed a model that illustrates our experience and involves 5 interconnected dimensions: developing a theoretical understanding of power processes, critically observing live therapy, noticing and attending to the felt experience of witnessing power, engaging in transformative discussion, and applying to personal practice (illustrated in Fig. 1).

\section{Developing a Theoretical Understanding of Power Processes}

We noticed that when themes including trust, communication, control and influence, vulnerability, or attunement were present in the therapy room, there was often some flow of power occurring in the moment. For example, after observing one therapy session where a heterosexual couple was discussing the female partner's difficulty trusting in the relationship, we identified that trust is inherently connected to power. The last author reflected, 'It's like she can't trust because she lives in a patriarchal world where she doesn't 
Fig. 1 Illustration of the five dimensions of learning to embody a relational power lens

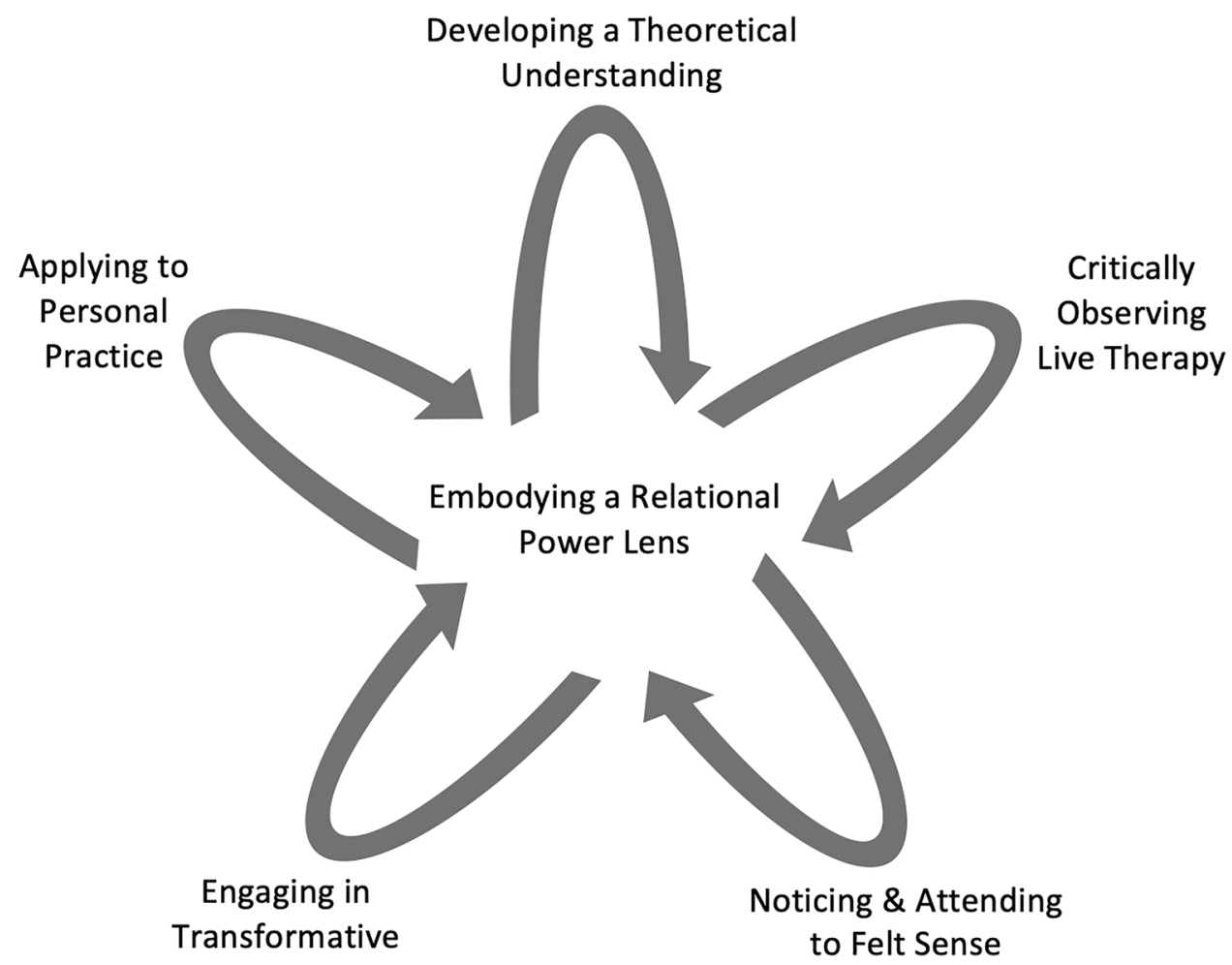

think relationships between women and men are safe. She doesn't have models of that." These themes joined our theoretical understanding of the flow of power in relationships and we can now use them as flags to identify power processes in our clinical work. For example, if the concept of trust is brought up by a client in therapy, we can use this as a cue to explore and understand potential associated power processes.

In this way, development of a raised awareness and conceptual understanding of relational power processes became an integral dimension in our process of embodiment. Engagement in this study increased our awareness of the shifting nature of power and the need to learn and relearn the ways in which power exists in relationships. Rooting our understanding in the theoretical model, SERT, provided a guide through which to analyze and understand what we were witnessing. Through our observations, the notion that power is not stagnant as relational systems and society continue to evolve and change became real to us.

\section{Critically Observing Live Therapy}

By critical observation, we refer to viewing live therapy sessions, analyzing the presence and processes of power between clients, therapists, and larger social discourses, and reflecting upon those analyses both internally and through documentation and coding. We experienced this as different from other observations we had done in class assignments where the focus wasn't specifically on the flow of power. Our critical analyses of observed therapy centered on identifying power processes, identifying adherence to SERT, noting missed opportunities for engaging with power, and assessing the perceived impact of power in the room.

One specific and persistent dynamic we noted often was the enactment of gendered social scripts and the ways a therapist's actions reinforced or interrupted an inequitable flow of gendered power: "[The therapist] was prioritizing [the male partner's] experience and his understanding of the situation and minimizing [the female partner's]. And the other thing that was being ignored and not interrupted [i.e., acknowledging and processing it] was the female partner's attunement to him and to his concern." [Second author].

Incorporating our evolving relational power lens enabled us to identify when observed therapists missed an opportunity to interrupt a power imbalance in session, which often reinforced an inequitable power balance in the couple unit. For example, in one discussion, we reflected on the experience of witnessing a male partner dismiss his female partner by invalidating her experience and questioning her memory of events that took place. This was uninterrupted by the therapist, which in turn reinforced an imbalanced power dynamic. The first author reflected, "[The therapist] letting all of that slide reinforces the fact that it's appropriate behavior; the therapist is almost giving [the male partner] permission to engage like that." 
Two key themes emerged from our critical observation: the first was the impact of observing varying skill levels and the second was the development of a critical self-observer.

\section{Impact of Observing Varying Skill Levels}

We discussed the different experiences of observing clinicians less experienced in SERT compared to when we observed highly experienced clinicians who expertly adhered to the SERT model. As the fourth author stated, “There's less to critique with someone who's been practicing for years." The first author described the differing cognitive process that happens when watching a therapist-in-training as compared to a clinician seasoned in the model.

It was more work [to identify power processes]. [Power] is not being explicitly called out as much. It feels like more of a creative process to imagine what we would do differently, where, at least in my experience, when I'm watching [faculty member] do therapy it feels like, oh, this is the way it should be done and it's harder to think of alternatives.

\section{Developing a Critical Self-Observer}

We noticed a common theme emerge in our analysis where we turned the focus of critical observation inward to our own practice, which we came to define as the development of a critical self-observer. The first author reflected,

During and after sessions... I'll think about moments where I may have reinforced a power imbalance and I'll think about how this may have been informed by [the clients'] sociocultural experience... I might have reinforced a gender stereotype that I don't think was very helpful. [I'll ask myself] how could I have done that differently? When this comes up again, how can I address that more directly or how can I interrupt it?

\section{Noticing and Attending to the Felt Experience of Witnessing Power}

While observing live therapy and in discussion, we noticed that witnessing power processes elicited our own emotional and somatic responses with varying levels of intensity, and it became apparent that identifying and processing such responses is critical to identifying when a power dynamic is present and needs attention: "Because of this study, I have this felt sense. I feel it in my body when something inequitable is happening in the room." [Fourth author].

Once this felt sense was identified, we worked to acknowledge our own sociocultural context and potential accompanying assumptions. For example, the first author reflected on her reaction to the role of race in the therapeutic relationship,
"Right now I feel pretty activated around white privilege and white supremacy and the ways that I may enact it or I may witness my clients enact or respond to it."

In another example, the topic of one observed session centered around infidelity with a heterosexual couple where we observed a significant power imbalance that was informed by gender, age, and the male partner's infidelity. The relational dynamic in the session allowed the female partner to take on significant responsibility and guilt, without the therapist challenging the male partner to access relational responsibility. After observing this session we discussed our shared belief that the female partner was owed attunement and the third author, The third author shared, "I guess this is hitting buttons for me, too, because that was definitely something I really wanted when I was in couples therapy; it felt like our therapist overfocused on why I was "putting up with" the behaviors from my partner rather than [the therapist] interrupting and exploring his behaviors that were emotionally abusive." As suggested by Garcia et al. (2015), we found that awareness of our emotion around power enabled us to both avoid reactive responses or blindness to otherwise taken-for-granted power processes and to consider how best to appropriately and effectively take action.

\section{Engaging in Transformative Discussion}

Transformative discussion refers to engaging in structured, reflexive conversations after viewing recorded therapy sessions, which acted as a catalyst for other dimensions of this model. As described in the method section, these structured conversations were guided by three questions: (a) What power processes did you observe? (b) What was your experience witnessing these power processes? (c) What might you take away from this observation? These reflexive conversations allowed us to build awareness of the nuance of power in relationships, to explore alternative therapeutic interventions, and to examine our sociocultural contexts and perspectives.

\section{Building Awareness of the Nuance of Power}

By discussing particular moments and themes in our observations, we became more aware of the nuance of power. For example, in one discussion about an observed session, we reflected on nuances of gendered power within the context of a couple where the male partner was struggling to access his own vulnerability and attune to his partner. Discussion allowed us to share experiences and understanding to develop and enhance our collective knowledge.

[First author]: I was just thinking about how much more complex gendered power gets because this man experienced so much abuse from his mother, who is 
a woman. So to then try and see women as inherently having less [societal] power than men feels so much more challenging because that was not what his experience was like.

[Fourth author]: It makes me think about how much more the male client would be ready to identify with a father's role as being a protector and that's not just a [social] gender discourse, that literally comes from a trauma history. And then also, how confusing it would feel to see your father, who you see as someone who could potentially protect you, try to protect you and fail...

[Last author]: Your identification is a good example of sociocultural attunement, recognizing his need to be the protector as also related to his views of his father, who, on one hand should have fit that societal stereotype and wasn't able to. So then what does he do with all these conflicting internalized experiences? You wouldn't get that if you weren't understanding his view of his father in light of the expectations for men.

\section{Exploring Alternative Interventions}

By discussing and exploring alternatives together, we expanded our understanding of interventions and of the therapist's role and were better able to envision our own use of this model in our personal practice. After one observed couple therapy session, the first author reflected on an alternative intervention:

[The therapist] could have tuned into him more to see if he was listening, to see if he was picking up on the right things, like was he hearing what she was saying? Otherwise, it would kind of be a wash, in a way, because he's tuned out because he's mad and only hearing the attacks against him.

\section{Examining Sociocultural Context and Challenging our Perspectives}

While reviewing our discussions, we noticed consistent processing of our own sociocultural context, lived experiences, and assumptions. Reflecting individually on our sociocultural experience was important, but group discussion brought an increased sense of accountability to reflect and challenge our own assumptions.

There's something that happens when you say it out loud [in this group], like I have this particular reaction when I see male partners using the language of emotional vulnerability in a way to manipulate the conversation... I feel it in my body, and it really is hard for me to sit with sometimes, but now that I've said it out loud, I have to address it and work to understand [my reaction]. [First author]

It felt important to consider the role of therapist power in the therapeutic relationship, including how our social identities intersect with that power. In one discussion, we reflected on the way an observed clinician used their power as a therapist to invite dialogue about mutuality within a queer relationship. In this transformative conversation, we discussed the complexity of therapist power and the importance of finding balance between imposing a social justice lens onto clients and compassionately inviting in our shared beliefs around ethical responsibility. That is, larger societal power issues often manifest within interpersonal relationships, and we have a responsibility to use our power to explore potential power processes as they occur and invite space for consciousness-raising (D’Arrigo-Patrick et al., 2017).

[Third author]: I think what's important to me about that is that by taking a position, I'm not wanting [clients] to assume that I am an expert or that I' $m$ a leader, just because I have an opinion. My position shouldn't automatically assume hierarchy.

[Last author]: Well, I think that's the dilemma. I feel like we're trying to avoid hierarchy. And yet we have to use our knowledge and our skills in ways that are hierarchical.

Many of our discussions were occurring during the racial justice protests in Summer 2020. In a conversation about the intersection of therapist power and race, the fourth author reflected on an observed therapist's choice to utilize psychoeducation in favor of sociocultural attunement in a session and the ways that, as white or white-passing therapists in training, we may uphold white supremacy in the choices we make in the therapeutic process.

I think that there's this piece of white supremacy here: That we feel we need to be in the expert role and we need to have the language and the tools and have the right answers. And so I think that it is something as therapists, especially as white therapists, that we have to look at in ourselves.

\section{Applying to Clinical Practice}

We found two components of applying this experience to our own practice: one involving a theoretical and abstract application and the other a reflection on actual application. Through observation and discussion, we often imagined how we might respond to a moment in a session, how we might connect with a particular client, or what we might want to do differently. For example, we reflected on the pace of therapy and the importance of using an intentional slowness to be able to understand power processes. In one reflexive 
conversation the last author reflected, "It's almost paradoxical, isn't it? It's like when you go slower you actually might get more done because the slowness has a focus to it."

We also developed more confidence in our ability to address power dynamics in-session After one session when we observed a clinician explicitly address power the first author reflected, 'I' $m$ feeling some inspiration to be riskier in naming power ... I think that it takes a certain boldness to be authentically transparent and to name many things that we see in a session and... I've been playing around with that."

Our discussions often included reflections on how this new integrated sense of understanding power might show up, or already did show up, in our personal practice. In one reflexive conversation, the fourth author shared,

In my own internal process as a therapist if I choose to track power in the session... There usually is a point in the session when I'm like, "oh, now it's relevant, and I'm so glad I've been tracking this the whole time." So now I can bring it in, in this way. And if it doesn't get brought up in the session then I still have all of this information because I've been tracking it the whole time, and I don't think that's something I would have done had we not had all these conversations.

\section{Embodiment of a Relational Power Lens}

As interconnected themes emerged in the analysis of our learning experience, each brought new understanding to our framework of relational power. Overall, we developed an embodied consciousness of this framework-experienced as the felt sense and automatic process of incorporating a relational power lens into practice as a therapist and into the lens through which we experience the world more broadly. We described this automatic process as the development of a critical consciousness; once we became aware of the always-present nature of power, we could no longer not see it, regardless of what model or intervention was in use. In one conversation, the second author, the second author, shared, "This is not... a lens that I take on and off at specific strategic moments in therapy; this has become something much more integrated into who I am... it's become part of my identity."

\section{Discussion}

Participating in a research study that involved recognizing power dynamics in couple therapy sessions was a transformative learning process. Our most important finding is that we moved from a cognitive understanding of power and equity in therapy to what we experienced as embodiment of a relational power lens that became real to us, and similar to what Rober (2020) called skilled intuition, an automatic way of seeing and responding, that we internalized through five interrelated dimensions of our experience. While specific to our own learning, each dimension of the grounded theory model presented here (Fig. 1) helps to inform understanding of elements that may contribute to an increased ability of couple and family therapists to recognize and address power and equity issues in their work.

\section{Embodiment of a Relational Power Lens}

The somatic nature of our embodied experience of a relational power lens is important. Similar to the experience of systems thinking, once we saw and felt power processes, we could no longer "unsee" or "unfeel" them. This is comparable to the process described by Esmiol and colleagues (2012) as a personal lens through which contextual consciousness was applied. Our process of embodied learning engaged us at a visceral, personally integrated level that was different from classroom activities and usually not possible in clinical supervision. It involved the kind of in-depth focused reflection on moment-to-moment clinical processes suggested by Rober (2020) as needed to develop more intuitive, less cognitive clinical processing.

Our findings also align with neurobiological understandings that for new narratives to move from rhetorical to embodied and applied requires affective engagement, focused attention, and shared reflection (Siegel, 2019; Zimmerman, 2018). This is especially true when transforming taken-for-granted nonconscious societal discourses that maintain institutionally supported power inequalities (Combs \& Freedman, 2012).

\section{Developing Theoretical Understanding of Power Processes}

Our findings point to the importance of bringing a focused lens that involves a social justice-related component, such as SERT, from which to engage in research or educational learnings in order to develop a more embodied understanding of power. This type of theoretical framework is especially important to MFTs who think systemically and work with relational systems at varying levels, where the flow of power is always happening (Wetherell, 2012). When applied to issues such as trust, communication, control, vulnerability, and attunement, we found we began to attend more viscerally to how relational power is always at play and available for processing and to automatically become curious about the complexities involved.

Similarly to participants in the Esmiol et al. (2012) study, we moved from raised awareness to an intentional, automatic new lens. Our experience also aligns with findings that when clinicians practiced sociocultural attunement, they 
"naturally" and intentionally accessed an internalized contextual lens through which they connected immediate client experience to social discourse and societal power processes (Pandit et al., 2014). We came to understand that ongoing learning and development of our theoretical framework will be imperative to maintaining an equitable practice, particularly as society continues to shift and grow.

\section{Critically Observing Live Therapy}

A key component to embodying a sociocontextual lens is that we began to develop and incorporate a critical selfobserver into our work as clinicians, often reflecting on and evaluating our engagement with power in our personal practice. The value of critical observation was magnified when various perspectives were brought into the room. Witnessing more seasoned SERT therapists provided important positive examples, but sometimes made these therapeutic interventions seem deceptively simple. Witnessing therapists-intraining was a helpful component that created an engaged critical thinking process for us in which we often identified missed opportunities to address power issues or considered alternative interventions.

Critical observation in a research context was quite different from other observation tasks within our clinical training, both in classes and in supervision groups. The structure of witnessing others do therapy seemed to create space to more critically analyze the process of what was and what was not happening without the delicacy required in a personal or group supervision. The goal of this observation was also different from the observation tasks in clinical training or supervision in that our goal was to simply identify and understand what power processes were happening as opposed to the goal of directly influencing treatment planning.

\section{Noticing and Attending to the Felt Experience of Witnessing Power}

Our findings highlight the importance of developing emotional awareness in social justice related work (Garcia et al., 2015). As our embodiment grew, our bodies sometimes told us where to look, and we determined that tending to our own experience was important. When we moved toward our own reactions, we tended to learn more and were able to expand our understanding of both our reactions and of power processes that may have been relevant in the therapy room. Recognizing that anxiety around engaging with power is normative and that our confidence grew as we confronted this fear together over the duration of our research is an important take-away from this study.

\section{Engaging in Transformative Discussion}

The integrative and transformative potential of interpersonally attuned dialogue is well documented in our field (Anderson \& Gehart, 2021; Siegel, 2019). Dialoguing inspired by our guiding questions enhanced and integrated our understanding and experience of relational power. Through dialogue our understanding of the nuance of power expanded and broader themes emerged. We were able to discuss these nuances together, explore alternative therapeutic interventions to deepen our understanding of the application of a relational power lens, and collectively examined our sociocultural contexts and perspectives.

Naming and discussing observations made themes and concepts more concrete and integrated and increased accountability, which felt like a different experience than when we viewed therapy recordings on our own. Our conversations were focused and supported by a mentor who helped to provide structure, summarized, raised new questions, and named processes. While the structure allowed our conversations to stay within a particular frame, the open-ended nature of our conversation and trust in the evolving learning process points to the value of the dialogue itself. We didn't enter these conversations with a particular outcome in mind; the purpose was simply to learn together, and this allowed us the space to engage reflectively, rather than with debate or seeking finality.

\section{Applying to Clinical Practice}

Our findings suggest the value of developing an embodied sense of relational power before and during clinical training. We began engaging in this study before we began the clinical practicum portion of our C/MFT training. Development of an embodied relational power lens allowed us to envision applying to our own practice and increased our sense of confidence in addressing relational power dynamics in our clinical work. Once we began seeing clients, it then helped us reflect on our own practice, which we described as the development of a critical self-observer. The final key to this embodied understanding of a relational power lens clicked when we started to see clients in our practicum.

\section{Implications for Training and Practice}

Dominant cultural narratives reflect the interests of those with more social power and are constructed in ways that sustain these power relations, yet tend to be so taken-forgranted that people do not see or recognize them (Combs $\&$ Freedman, 2012). Awareness of social power processes is an important step in recognizing them in therapy, but cognitive awareness is not likely to lead to embodied response without more focused affective interpersonal 
engagement (Siegel, 2019; Zimmerman, 2018). Our findings suggest that if training programs and supervisors hold the goals of preparing therapists to recognize and address the effects of societal power processes in practice, it will be helpful to develop learning activities that facilitate this process. Analysis of our learning experience brought some key suggestions to the forefront, as highlighted in Table 1.

Firstly, our grounded theory model can guide training initiatives in structuring clinical observation processes to incorporate each of the dimensions we identified in order to allow clinicians-in-training to embody a relational power lens into their developing practice. Instead of simply observing therapy sessions to learn a model, therapists-in-training may benefit from observing and coding therapy sessions based on their adherence to a model like SERT and identifying what power processes are happening in each session. Additionally, our findings suggest the importance of incorporating a transformative discussion format designed to critically assess the presence of and engagement with power, the observer's experience of witnessing power, and inviting participants to envision how they might apply to their own personal practice.

We also identified the value of witnessing varying skill levels when observing therapy sessions. Training programs may benefit from incorporating observation of therapists-in-training as opposed to solely viewing expert therapists. Additionally, through the experience of embodiment, we developed a critical self-observer that we found to be impactful in our own personal practice; encouraging this type of self-reflection within clinical training may allow therapists-in-training to more fully embody an equitable practice. Notably, MFT programs and supervisors may want to consider how to engage therapists-in-training in focused coding and critical reflection distinct from usual supervision, perhaps as an activity corresponding to or parallel with a class or supervision group.

Our findings also point to the value of a dialogical approach to learning, both in the classroom and beyond (e.g., Anderson \& Gehart, 2021). Clinicians who want to evolve their ability to attend to the sociopolitical aspects of therapy may benefit from an ongoing group that provides this kind of engagement and feedback. Finally, this experience made especially evident the value of research as a way to learn and develop as clinicians. Incorporating a clinical research component into training or practice may offer a more integrative experience of clinical development. The family therapy field was started by observation, reflection, and expanding based on what was learned in the moment. Our study highlights the value of the tradition of a group studying and learning from their own practice (e.g., Knudson-Martin et al., 2015).

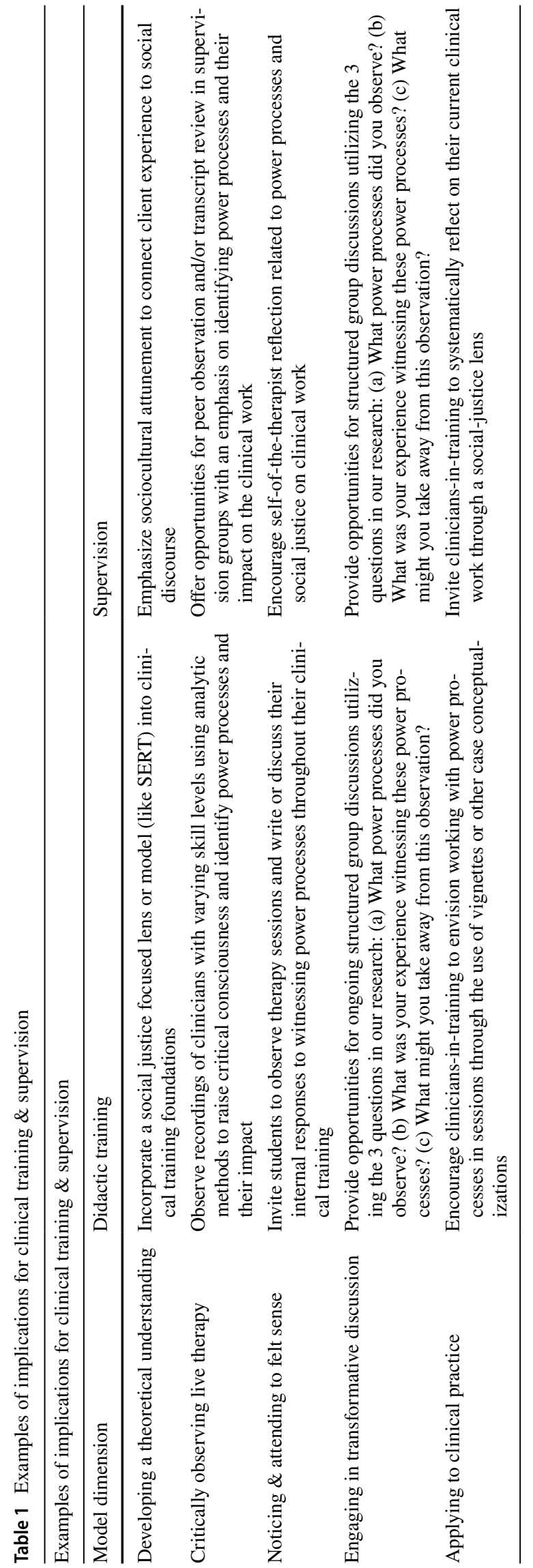




\section{Limitations and Future Directions}

A central limitation to our findings is that participatory action research is limited to the few experiences involved, which in our case included four therapists-in-training and one faculty member, who all share similar white, or whitepassing, female identities. This means that our findings were developed within the context of whiteness and may be limited in their application to a more diverse group of therapists-in-training. In future directions, we would want to incorporate even more awareness of how our own privilege was influencing our experiences. Additional research would need to be conducted in order to understand how this model fits into the experience of therapists-in-training with varying backgrounds and identities. This study was also centered within the context of SERT, a model that is rooted in understanding the flow of power in relationships. The experience of therapists-in-training might look different if they were to engage in this process from a different theoretical orientation. Additionally, more research needs to be done in order to understand the impact and process of implementing of this type of learning model into clinical training programs.

In our analysis, several themes emerged as components of power particularly relevant to couple and family therapy that need to be developed further. These include the roles of trust, communication, control and influence, vulnerability, and attunement as identifiers for the occurrence of power processes. We hope to see future research explore these themes in relation to power in order to increase our understanding of their potential impact on clinical practice. We look forward to witnessing the body of research on equitable practice continue to grow in order to increase the field's understanding of the role of social inequities in relationships and to allow clinicians to more effectively address gendered, racial, and other inequities that present in client relationships.

Funding No funds, grants, or other support were received to assist with the preparation of this manuscript.

\section{Declarations}

Conflict of interest The authors have no relevant financial or non-financial interests to disclose.

\section{References}

Almeida, R. V, \& Tubbs, C. Y. (2020). Intersectionality: A liberation based healing perspective. In K. S. Wampler, R. B. Miller, \& R. B. Seedall (Eds.). The Handbook of Systemic Family Therapy,
(Vol. 1, pp. 225-249). Wiley. https://doi.org/10.1002/9781119790 181.ch10

Almeida, R. V. (2018). Liberation based healing practices. Institute for Family Services. https://doi.org/10.1093/acrefore/9780199975 839.013.1159

Almeida, R. V., Dolan-Del Vecchio, K., \& Parker, L. (2008). Transformative family therapy: Just families in a just society. Pearson Education. https://doi.org/10.1111/j.1752-0606.2009.00190.x

Anderson, H., \& Gehart, D. (2021). Collaborative-dialogic practice: Generative relations and conversations across contexts and cultures. Routledge.

Baima, T., \& Sude, M. E. (2020). What white mental health professionals need to understand about whiteness: A Delphi study. Journal of Marital and Family Therapy, 46(1), 62-80. https://doi.org/10. $1111 /$ jmft. 12385

Bell, L. A. (2007). Theoretical foundations for social justice education. In M. Adams, L. A. Bell, \& P. Griffin (Eds). Teaching for diversity and social justice, (2nd ed., pp. 11-14). Routledge. https://doi.org/ $10.4324 / 9781315775852$

Castronova, M., ChenFeng, J., \& Zimmerman, T. S. (2020). Supervision in systemic family therapy. In K. S. Wampler, R. B. Miller, \& R. B. Seedall (Eds.). The Handbook of Systemic Family Therapy (Vol. 1, pp. 577-600). Wiley. https://doi.org/10.1002/9781119438 519.ch25

Charmaz, K. (2014). Constructing grounded theory: A practical guide through qualitative analysis (2nd ed.). Sage.

ChenFeng, J., Castronova, M., \& Zimmerman, T. (2017). Safety and social justice in the supervisory relationship. In R. Allan \& S. S. Poulsen (Eds.). Creating cultural safety in couple and family therapy: Supervision and training (pp. 43-56.). AFTA Springer Briefs in Family Therapy. Springer. https://doi.org/10.1007/ 978-3-319-64617-6_5

Coghlan, D., \& Brannick, T. (2005). Doing action research in your own organization (2nd ed.). Sage Publications. https://doi.org/10.1080/ 14767333.2015.1049453

Combs, G., \& Freedman, J. (2012). Narrative, poststructuralism, and social justice: Current practices in narrative therapy. The Counseling Psychologist, 40, 1033-1060. https://doi.org/10.1177/ 0011000012460662

D’Arrigo-Patrick, J., Hoff, C., Knudson-Martin, C., \& Tuttle, A. R. (2017). Navigating critical theory and postmodernism: Social justice and therapist power in family therapy. Family Process., 56, 574-588. https://doi.org/10.1111/famp.12236

Dolan-Del Vecchio, K. (2019). Dismantling white male privilege within family therapy. In M. McGoldrick \& K. V. Hardy (Eds.). Re-visioning family therapy: Addressing diversity in clinical practice (3rd ed., pp. 226-235). Guilford.

Esmiol, E. E., Knudson-Martin, C., \& Delgado, S. (2012). Developing a contextual consciousness: Learning to address gender, societal power, and culture in clinical practice. Journal of Marital and Family Therapy, 38, 573-588. https://doi.org/10.1111/j.17520606.2011.00232.x

Falicov, C. V. (2014). Psychotherapy and supervision as cultural encounters: The multidimensional ecological comparative approach framework. In C. A. Falender, E. P. Shafranske, \& C. J. Falicov (Eds.). Multiculturalism and diversity in clinical supervision: A competency-based approach (pp. 29-58). American Psychological Association. https://doi.org/10.1037/14370-002

Garcia, M., Košutić, I., \& McDowell, T. (2015). Peace on earth/war at home: The role of emotion regulation in social justice work. Journal of Feminist Family Therapy, 27, 1-20. https://doi.org/10. 1080/08952833.2015.1005945

Hardy, K. V., \& Bobes, T. (2017). Core supervisor competencies. In K. V. Hardy \& T. Bobes (Eds.). Promoting cultural sensitivity in supervision: A manual for practitioners (pp. 3-14). Routledge. https://doi.org/10.4324/9781315225791-4 
Hardy, K. V. (2017). "Naming it and claiming it"-Embracing your identity as an activist (supervisor, educator, therapist). In K. V. Hardy \& T. Bobes (Eds.). Promoting cultural sensitivity in supervision: A manual for practitioners (pp. 25-28). Routledge. https://doi.org/10.4324/9781315225791-4

Hardy, K. V., \& McGoldrick, M. (2019). Re-visioning family therapy training. In M. McGoldrick \& K. V. Hardy (Eds.). Re-visioning family therapy: Addressing diversity in clinical practice, (3rd ed., pp. 477-495). Guilford.

Hoff, C., \& Distelberg, B. (2017). Developmental pedagogy in marriage and family therapy education: Preparing students to work across epistemologies. Journal of Family Theory \& Review, 9(3), 382-390. https://doi.org/10.1111/jftr.12203

Hoff, C., Lobo, E., Knudson-Martin, C., \& Distelberg, B. (2018). Developmental epistemology in MFT education: A narrative analysis of students' experiences. Journal of Systemic Therapies, 37(2), 17-28. https://doi.org/10.1521/jsyt.2018.37.2.17

Holyoak, D., McPhee, D., Hall, G., \& Fife, S. (2020). Micro-level advocacy: A common process in couple and family therapy. Family Process, Advanced on-line publication. https://doi.org/ 10.1111/famp. 12620

Kim, L, Esmiol Wilson, E., ChenFeng, J., \& Knudson-Martin, C. (2017). Toward safe and equitable relationships: Sociocultural attunement in supervision. In R. Allan \& S. S. Poulsen (Eds.). Creating cultural safety in couple and family therapy: Supervision and training. (pp. 57-70). AFTA Springer Briefs in Family Therapy. Springer. https://doi.org/10.1007/ 978-3-319-64617-6_6

Knudson-Martin, C., Kim, L., Gibbs, E., \& Harmon, R. (2021). Sociocultural attunement to vulnerability in couple therapy: Fulcrum for changing power processes. Family Process. Advanced online publication. https://doi.org/10.1111/famp.12635

Knudson-Martin, C. (2013). Why power matters: Creating a foundation for mutual support in couple therapy. Family Process, 52, 5-18. https://doi.org/10.1111/famp.12011

Knudson-Martin, C., \& Huenergardt, D. (2010). A socio-emotional approach to couple therapy: Linking social context and couple interaction. Family Process, 49, 369-386. https://doi.org/10. 1111/j.1545-5300.2010.01328.x

Knudson-Martin, C., Huenergardt, D., Lafontant, K., Bishop, L., Schaepper, J., \& Wells, M. (2015). Competencies for addressing gender and power in couple therapy: A socio-emotional approach. Journal of Marital and Family Therapy, 41, 205-220. https://doi.org/10.1111/jmft.12068

Knudson-Martin, C., \& Mahoney, A. (2009). Couples, gender, and power: Creating change in intimate relationships. Springer. https://doi.org/10.1891/9780826117564

Laszloffy, T., \& Habekost, J. (2010). Using experiential tasks to enhance cultural sensitivity among MFT trainees. Journal of Marital and Family Therapy, 36(3), 333-346. https://doi.org/ 10.1111/j.1752-0606.2010.00213.x

McDowell, T. (2015). Applying critical social theories to family therapy practice. AFTA SpringerBriefs in Family Therapy. Springer. https://doi.org/10.1007/978-3-319-15633-0

McDowell, T., Fang, S.-R., Young, C. G., Khanna, A., Sherman, B., \& Brownlee, K. (2003). Making space for racial dialogue: Our experience in a marriage and family therapy training program. Journal of Marital and Family Therapy, 29(2), 179-194. https:// doi.org/10.1111/j.1752-0606.2003.tb01199.x

McDowell, T., Knudson-Martin, C., \& Bermudez, J. M. (2019). Third-order thinking in family therapy: Addressing social justice across family therapy practice. Family Process, 58, 9-22. https://doi.org/10.1111/famp.12383

McDowell, T., \& Shelton, D. (2002). Valuing ideas of social justice in MFT curricula. Contemporary Family Therapy, 24, 313-331. https://doi.org/10.1023/A:1015351408957
McGeorge, C. R., Carlson, T. S., Erickson, M. J., \& Guttormson, H. E. (2006). Creating and evaluating a feminist-informed social justice couple and family therapy training model. Journal of Feminist Family Therapy, 18(3), 1-38. https://doi.org/10.1300/ J086v18n03 01

Mertens, D. M. (2007). Transformative paradigm. Journal of Mixed Methods Research, 1, 212-225. https://doi.org/10.1177/15586 89807302811

Mertens, D. M. (2009). Transformative research and evaluation. Guilford Press.

Mock, M. R. (2019). Social justice in family therapy training: The power of personal and family narratives. In M. McGoldrick \& K. V. Hardy (Eds.). Re-visioning family therapy: Addressing diversity in clinical practice (3rd ed., pp. 496-511). Guilford Press.

Murphy, M. J., \& Hecker, L. L. (2020). Ethical and legal issues unique to systemic family therapy. In K. S. Wampler, R. B. Miller, \& R. B. Seedall (Eds.). The Handbook of Systemic Family Therapy (Vol. 1, pp. 533-554). Wiley. https://doi.org/10. 1002/9781119438519.ch23

Nixon, D., Marcelle-Coney, D., Torres-Greggory, M., Huntley, E., Jacques, C., Pasquet, M., \& Ravachi, R. (2010). Creating community: Offering a liberation pedagogical model to facilitate diversity conversations in MFT graduate classrooms. Journal of Marital and Family Therapy, 36(2), 197-211. https://doi.org/ 10.1111/j.1752-0606.2009.00180.x

Pandit, M., Kang, Y. J., ChenFeng, J., Knudson-Martin, C., \& Huenergardt, D. (2014). Practicing socio-cultural attunement: A study of couple therapists. Journal of Contemporary Family Therapy, 36, 518-528. https://doi.org/10.1007/s10591-014-9318-2

Petty-John, M. E., Tseng, C.-F., \& Blow, A. J. (2020). Therapeutic utility of discussing therapist/client intersectionality in treatment: When and how? Family Process, 59(2), 313-327. https:// doi.org/10.1111/famp.12471

Piercy, F., Earl, R., Aldrich, R., Nguyen, H., Steelman, S., Haugen, E., Riger, D., Tsokodayi, R. T., West, J., Keskin, Y., \& Gary, E. (2016). Most and least meaningful learning experiences in marriage and family therapy education. Journal of Marital and Family Therapy, 42(4), 584-598. https://doi.org/10.1111/jmft. 12176

Rambo, A. (2018). Introduction to the special section: Being change agents in a time of change (while ourselves changing). Journal of Systemic Therapies, 37, 15-17. https://doi.org/10.1521/jsyt. 2018.37.1.15

Rober, P. (2020). The dual process of intuitive responsivity and reflective self-supervision: About the therapist in family therapy practice. Family Process. https://doi.org/10.1111/famp.12616

Siegel, D. J. (2019). The mind in psychotherapy: An interpersonal neurobiology framework for understanding and cultivating mental health. Psychology and Psychotherapy: Theory, Research, and Practice, 92, 224-237. https://doi.org/10.1111/papt.12228

Smoliak, O., Rice, C., Knudson-Martin, C., Briscoe, C., LeCouteur, A., LaMarre' A., Tseliou, E., Velikonja, L., Myers, M., Addison, M., \& Vesely, L. (2021). Denials of responsibility in couple therapy. Journal of Couple and Relationship Therapy. Advanced online publication. https://doi.org/10.1080/15332691. 2021.1967248

Stone, D. J., \& ChenFeng, J. L. (2020). Finding your voice as a beginning marriage and family therapist. Routledge. https://doi. org/10.4324/9781315266190

Watson, M., Bacigalupe, G., Daneshpour, M., Wen-Jui, H., \& ParraCardona, R. (2020). COVID-19 interconnectedness: Health inequity, the climate crisis, and collective trauma. Family Process, 59, 832-846. https://doi.org/10.1111/famp.12572

Wetherell, M. (2012). Affect and emotion: A new social science understanding. Sage. https://doi.org/10.4135/9781446250945 
Zetzer, H.A. (2016). Power and privilege in supervision: Multicultural feminist reflections on practice. In K.V. Hardy \& T. Bobes (Eds.). Culturally sensitive supervision and training: Diverse perspectives and practical applications (pp. 27-34). https://doi. org/10.4324/9781315648064-4

Zimmerman, J. (2018). Neuro-narrative therapy: New possibilities for emotion-full conversations. Norton.
Publisher's Note Springer Nature remains neutral with regard to jurisdictional claims in published maps and institutional affiliations. 